\section{Lonar Timetable}

OF the five landing sites in the equatorial region of the Moon which have been chosen as smooth enough for a manned landing, three are in the running for the Apollo 11 mission. What governs the choice of site is the angle of elevation of the Sun at the time of landing, and if launch goes ahead as planned on July 16 , the landing will be at site 2 in Mare Tranquillitatis. On July 16 , the launch window is from 9.32 to 13.54 Eastern Daylight Time. But if the launch has to be postponed, then the landing could be at site 3 in Sinus Medii with a launch between 11.32 and 14.02 on July 18 , or at site 5 in Oceanus Procellarum with a launch between 12.04 and 14.39 on July 21 . If a serious delay crops up, then similar groups of launch dates are available in August and in September.

In essence, the flight plan for Apollo 11 follows that for Apollo 10, but with the lunar landing occupying the time which the Apollo 10 crew spent on landmark tracking and lunar photography and with an extra orbit of the Moon fitted in so that the crucial landing sequence can be monitored with the 210-foot dish aerials at Goldstone, California, and at Parkes, Australia. After launch from complex 39-A at Cape Kennedy, Apollo 11 will be placed in a 100 nautical mile parking orbit while the spacecraft is checked. (As befits voyages of exploration, NASA describes its flight plans in nautical miles.) Assuming launch at the earliest opportunity at $9.32\left(\mathrm{ED}^{\prime} \mathrm{T}\right)$ on July 16, the Apollo command and service modules, still attached to the Saturn IV-B stage containing the lunar module, will be fired onto a course for the Moon at 12.16 ( 2 hours and 44 minutes after launch). Then, as usual, the command and service modules separate from the Saturn IV-B, turn through $180^{\circ}$, dock with the lunar module in the Saturn IV-B, and withdraw it from its casing. When the complete Apollo 11 unit is at a comfortable distance, the empty Saturn IV-B stage is fired out of the way into a solar orbit. The coast to the Moon lasts 73 hours 10 minutes, and on July 19 at 13.20 Apollo 11 will be injected into an elliptical lunar orbit, 60 nautical miles by 170 nautical miles. Three and a quarter hours later this will be changed into a 60 mile circular orbit, and the business of checking out the lunar module begins. The first stage in the landing sequence is to propel the lunar module so that it falls below and ahead of the command module (because, in a lower orbit, the spacecraft speeds up).

At an altitude of 50,000 feet and at a horizontal distance from the landing site of 260 nautical miles, the descent engine is fired to brake the speed of the lunar module from 1 mile per second so that it falls bchind the orbiting command module. At an altitude of 7,600 feet, a horizontal range of 26,000 feet, and a speed of 60 miles per hour, the lunar module is at a position which NASA terminology calls the hi-gate. When it enters the hi-gate the axis of the lunar module is horizontal with respect to the lunar surface- the position it was in when it separated from the command module-henceforth its attitude is gradually changed to the vertical for the landing sequence. From the hi-gate onwards the crew will be checking the condition of the landing site through the windows of the module. At 500 feet and a horizontal range of 2,000 feet (the lo-gate), the module is almost vertical, and from then on the landing sequence is semi-automatic. At touchdown the lunar module will be 240 miles behind the command module, and 4 days, 6 hours and 51 minutes out from the Earth.

The lunar module is to be on the Moon for 21 hours 27 minutes, with the crew spending something like 2 hours 40 minutes outside. The plan is for Armstrong to be the first to leave, climbing backwards down the ladder attached to one of the four legs of the module. On the second rung he is to deploy a fixed television camera on the module to record his first steps. In fact, Armstrong's left foot will be the first to test the consistency of the surface material, while his right rests in the dish-shaped footpad of the module. The first 5 minutes on the surface will be spent in acclimatization to the new environment (standing on one foot to check his balance, and so on) and in grabbing about two pounds of lunar soil in case the stay on the surface has to be cut short. Then Armstrong will take a television camera to record Aldrin's exit from the module, eventually setting up the camera 30 feet from the module to record their activities. At this point, if the strength of the signal being picked up at the Parkes dish is found not to be adequate for good pictures, an S-band aerial will be erected. Meanwhile Aldrin will be setting up a foil screen to collect particles in the solar wind, and moving about on the surface to see how well his spacesuit stands up to lunar conditions.

Together, the two astronauts are to inspect the condition of the lunar module, and remove the package of scientific instruments stowed away in the lower half of the module. Here Aldrin will be doing the lion's share of the work to give Armstrong, who will have been out for 25 minutes longer, some rest. The instruments are a laser reflector, and a package of seismic equipment, to be deployed well clear of the area which will receive the blast from the ascent engine (roughly 70 feet away). Then the business of collecting interesting-looking pieces of rock begins, with Aldrin picking up the items and Armstrong holding open the sample bags. Two cores going down to a depth of about a foot will also be collected. Aftcr about 2.5 hours, Aldrin will be the first to re-enter the lunar module, and Armstrong will pass the samples up to him along a conveyor belt.

The lower half of the lunar module then acts as a launching pad for the ascent stage. First the ascent stage climbs vertically for 14 seconds to a speed of 60 miles per hour, then tips over to an angle of $52^{\circ}$ and a further firing of $7 \cdot 25$ minutes to orbital velocity. The ascent stage is then in a 12 mile by 45 mile elliptical orbit which is changed into a circular orbit of 45 miles, 15 miles below the command module. A final rendezvous firing brings the two spacecraft together, 5 days and 8 hours out from the Earth. The mission then follows the Apollo 10 mission, with injection into a trajectory for the Earth after 59.5 hours in lunar orbit. Flight time to the Earth is also roughly 59.5 hours, and splashdown is to be in the Pacific just over eight days after launch, depending on which landing site is chosen. 